\title{
Mirena ${ }^{\circledR}$ removal from a
} nulliparous woman

I recently removed a Mirena ${ }^{\circledR}$ intrauterine system (IUS) from a lady who had a tight nulliparous cervix. I had to pull on the threads fairly firmly to get the IUS to come out from the cervix. When the IUS came out I noticed that the levonorgestrel-containing cylinder had become displaced and was near the top of the 'arms' of the IUS (Figure 1). I have never dilated a cervix for an IUS/ intrauterine device removal but perhaps, in retrospect, in this case it might have been a good idea. I was concerned that if the cylinder had become further displaced, it might have remained inside the uterine cavity after the main body of the IUS had been removed.

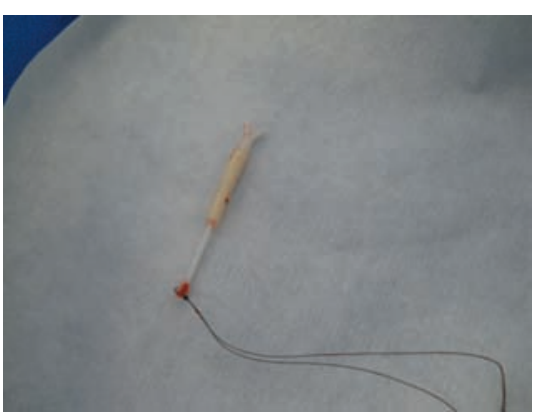

Figure 1 The displaced levonorgestrelcontaining cylinder can be seen near the top of the 'arms' of the intrauterine system.

I was wondering if other readers had come across this situation?

Alex Manning, DRCOG, DFSRH

Cambridgeshire Primary Care Trust, Burwell Surgery, Cambridge,UK; alex.manning@nhs.net

Competing interests None.

J Fam Plann Reprod Health Care 2011;37:191. doi:10.1136/fprhc-2011-0115 